\section{Cureus}

\title{
A Successfull Therapeutic Challenge: Local Reirradiation of Breast Cancer with a Single Dose of 18 Gy Intraoperative Radiation Therapy (IORT)
}

\author{
Elisabetta Bonzano ${ }^{1}$, Marina Guenzi ${ }^{2}$, Renzo Corvò ${ }^{3}$ \\ 1. Radiation Oncology, University of Genoa Ospedale Policlinico San Martino 2. Radiation Oncology, \\ University of Genoa Ospedale Policlinico San Martino 3. Department of Radiation Oncology, University \\ of Genoa Ospedale Policlinico San Martino
}

$\square$ Corresponding author: Elisabetta Bonzano, elisabettabonzano@gmail.com Disclosures can be found in Additional Information at the end of the article

\section{Abstract}

After standard treatment of primary breast cancer, local relapse can develop in a previously irradiated region. The decision to refer a patient for a second radiotherapy must be thoroughly evaluated due to the increased risk of side effects. We report a case of a 43-year-old Caucasian female with a history of left breast lumpectomy and radiation treatment in 1990 for an invasive ductal carcinoma who presented with a locoregional recurrence 19 years later. After careful evaluation, the patient has undergone a second breast-conserving surgery and successful reirradiation with $18 \mathrm{~Gy}$ single dose of intraoperative radiation therapy (IORT).

Categories: Radiation Oncology, Oncology

Keywords: breast cancer, intraoperative radiotherapy, locoregional recurrence, reirradiation

\section{Introduction}

Nowadays, breast conservative treatment, consisting of conservative surgery followed by adjuvant external whole breast irradiation (WBI), is the main strategy for early breast cancer patients [1-2]. After this approach in early breast cancer patients, the risk of a relapse at 10 years remains about 3\% - 5\% [3]. When relapse in an irradiated breast occurs, mastectomy is traditionally advised since repeat WBI is not recommended due to the high risk of severe late effects [3]. The aim of this case is to report a potential management adopted to achieve definitive local control in a relapse of breast cancer treated by lumpectomy and intraoperative radiation therapy (IORT).

Received 05/24/2017

Review began 05/27/2017 Review ended 06/15/2017 Published 06/20/2017

C) Copyright 2017

Bonzano et al. This is an open access article distributed under the terms of the Creative Commons Attribution License CC-BY 3.0., which permits unrestricted use, distribution, and reproduction in any medium, provided the original author and source are credited.

\section{Case Presentation}

On January 25, 1990, a 43-year-old woman underwent left breast conserving surgery with axillary lymph node dissection due to an invasive ductal carcinoma (IDC) pT1bN0 (0/13), $0.7 \mathrm{~cm}$ in the largest diameter. After that, she had adjuvant conventional whole breast irradiation with a total dose of 50 Gy in 25 daily fractions delivered over five weeks. Subsequently, she began an annual follow-up by surveillance mammography and ultrasonography. The patient had no evidence of disease until November 2009, when she had a recurrence of IDC, after 19 years of disease-free interval. Tumor size and immunohistochemistry, obtained from the pre-surgical biopsy, were both suitable for a new breast conservative surgical approach with simultaneous IORT. On January 20, 2010, she underwent left lumpectomy and two sentinel lymph nodes were 
removed for examination. Immediately after tumor resection, an exclusive 18 Gy IORT was performed on the surgical tumor bed of the remaining breast by using a mobile linear accelerator, LIAC (Sordina IORT Technologies S.p.A., Vicenza, Italy), located in the surgical room. A $6 \mathrm{MeV}$ electron energy was chosen, the beam's collimation was achieved by a $5 \mathrm{~cm}$ diameter perspex applicator, and a lead disk ( $7 \mathrm{~cm}$ in diameter) was inserted over the pectoralis major muscle to prevent chest wall irradiation. In vivo dosimetry using a miniature metal oxide semiconductor field effect transistor (micro-MOSFET) was applied. The final pathology demonstrated the tumor size to be $1.5 \mathrm{~cm}$ in maximum diameter and the lymph node status was negative. Estrogen receptor (measured by immunohistochemistry) was $96 \%$, progesterone was negative, the Ki67 index was 14\%, the human epidermal growth factor receptor-2 (HER-2) profile was negative, and the diagnosis of invasive ductal carcinoma was confirmed. Hormonal therapy was given due to the histological characteristics. The patient was seen for surveillance every six months during the first two years after treatment and once a year

thereafter. Now, seven years later, at our most recent follow-up in May of this year, the woman is disease-free and the aesthetic results are excellent with only a mild local fibrosis in the region treated.

\section{Discussion}

Locoregional recurrence after standard treatment of primary breast cancer represents a therapeutic challenge. It has been demonstrated that young age is directly related to the risk of developing a local recurrence, so it is considered an important prognostic factor [4], such as pathologic nodal involvement, and biologic subtype [5]. As stated by the Breast Cancer Expert Panel of the German Society for Radiation Oncology (DEGRO) practice guidelines [6], if an isolated ipsilateral breast tumor recurrence is of limited size $(<2-3 \mathrm{~cm})$, mammography shows unifocal disease, patient age $\geqslant 50$ years, if there is a long interval between primary treatment and recurrence ( $\geqslant 48$ months), and the patient expresses a preference for a second breast conservation followed by radiotherapy [6], a second breast-conserving approach can be technically feasible. According to the literature, the earlier that the patient has a relapse, the higher the likelihood is that the patient will have a worse overall or disease-free survival [7]. In regards to the management after a local recurrence, there are no standard guidelines [8]. Salvage mastectomy is the most common approach for operable ipsilateral breast relapse. However, a second conservative surgery with partial breast irradiation is being increasingly studied with the aim to improve local control, decreasing toxicity, and avoiding the risks of late effects occurring after a standard second-course whole breast irradiation. In the literature, the most studied approaches are external-beam irradiation and brachytherapy [9]. Our experience, here described, demonstrates that also individualized re-irradiation with IORT is a safe and feasible treatment with long-term local disease control (Table 1). 


\section{Cureus}

\begin{tabular}{|l|l|l|}
\hline & $\begin{array}{l}\text { Presented case. Reirradiation } \\
\text { with IORT }\end{array}$ & $\begin{array}{l}\text { Deutsch, et al. 2002 [10]. Re- irradiation with } \\
\text { EBRT (n = 39) }\end{array}$ \\
\hline First RT (Gy) EBRT & 50 & 50 (minimal) \\
\hline $\begin{array}{l}\text { Second RT (Gy) } \\
\text { Cumulative dose (Gy) }\end{array}$ & 18 (IORT) & 50 (minimal) \\
\hline $\begin{array}{l}\text { Interval between RT courses } \\
\text { (months) }\end{array}$ & 228 & 100 (minimal) \\
\hline $\begin{array}{l}\text { Local control } \\
\text { Toxicity }\end{array}$ & No recurrence at 84 months & Not available data \\
\hline
\end{tabular}

\section{TABLE 1: Comparison of the Described Case with Cases Treated with External Beam Radiation Therapy (EBRT)}

Gy: gray; IORT: intraoperative radiation therapy; RT: radiation therapy

\section{Conclusions}

Few data are available in the literature about reirradiation with a single dose of electron beam intraoperative radiotherapy. In a selected group of patients who have developed a locoregional recurrence, treatment with a second breast conservation surgery and IORT appears to be a valid alternative when compared to mastectomy. This approach allows for sparing of the organs at risk and can result in an acceptable cosmetic outcome.

\section{Additional Information \\ Disclosures}

Human subjects: Consent was obtained by all participants in this study. Conflicts of interest: In compliance with the ICMJE uniform disclosure form, all authors declare the following: Payment/services info: All authors have declared that no financial support was received from any organization for the submitted work. Financial relationships: All authors have declared that they have no financial relationships at present or within the previous three years with any organizations that might have an interest in the submitted work. Other relationships: All authors have declared that there are no other relationships or activities that could appear to have influenced the submitted work.

\section{References}

1. Bodilsen A, Offersen BV,Christiansen P, Overgaard J : Pattern of relapse after breast conserving therapy, a study of 1519 early breast cancer patients treated in the Central Region of Denmark 2000-2009. Acta Oncol. 2016, 55:964-69. 10.3109/0284186X.2016.1167955

2. Johns N, Dixon JM: Should patients with early breast cancer still be offered the choice of breast conserving surgery or mastectomy?. Eur J Surg Oncol. 2016, 42:1636-41. 10.1016/j.ejso.2016.08.016

3. Wadasadawala T, Vadgaonkar R, Bajpai J: Management of isolated locoregional recurrences in breast cancer: A review of local and systemic modalities. Clin Breast Cancer. 2017, pii: S1526- 
8209(16)30416-5. 10.1016/j.clbc.2017.03.008

4. van Laar C, van der Sangen MJ, Poortmans PM, et al.: Local recurrence following breastconserving treatment in women aged 40 years or younger: trends in risk and the impact on prognosis in a population-based cohort of 1143 patients. Eur J Cancer. 2013, 49:3093-101. 10.1016/j.ejca.2013.05.030

5. Mihalcik SA, Rawal B, Braunstein LZ, et al.: The impact of reexcision and residual disease on local recurrence following breast-conserving therapy. Ann Surg Oncol. 2017, 24:1868-73. 10.1245/s10434-016-5727-9

6. Harms W, Budach W, Dunst J, et al.: DEGRO practical guidelines for radiotherapy of breast cancer VI: therapy of locoregional breast cancer recurrences. Strahlenther Onkol. 2016, 192:199-208. 10.1007/s00066-015-0939-7

7. van der Sangen MJ, van de Poll-Franse LV, Roumen RM, et al.: The prognosis of patients with local recurrence more than five years after breast conservation therapy for invasive breast carcinoma. Eur J Surg Oncol. 2006, 32:34-38. 10.1016/j.ejso.2005.10.005

8. Anderson SJ, Wapnir I, Dignam JJ, et al.: Prognosis after ipsilateral breast tumor recurrence and locoregional recurrences in patients treated by breast-conserving therapy in five National Surgical Adjuvant Breast and Bowel Project protocols of node-negative breast cancer. J Clin Oncol. 2009, 27:2466-73. 10.1200/JCO.2008.19.8424

9. Marta GN, Hilal T, de Andrade Carvalho H: Reirradiation for locally recurrent breast cancer . Breast. 2017, 33:159-65. 10.1016/j.breast.2017.03.008

10. Deutsch M: Repeat high-dose external beam irradiation for in-breast tumor recurrence after previous lumpectomy and whole breast irradiation. Int J Radiat Oncol Biol Phys. 2002, 53:68791. 10.1016/S0360-3016(02)02785-2 